OPEN ACCESS

Approved by:

Frontiers in Neurology,

Frontiers Media SA, Switzerland

*Correspondence:

Lorenzo Rocchi

I.rocchi@ucl.ac.uk

tThese authors have contributed equally to this work

Specialty section

This article was submitted to

Movement Disorders,

a section of the journal

Frontiers in Neurology

Received: 28 November 2018 Accepted: 17 December 2018

Published: 08 January 2019

Citation:

Rocchi L, Suppa A, Leodori G, Celletti C, Camerota F, Rothwell J and

Berardelli A (2019) Corrigendum: Plasticity Induced in the Human Spinal

Cord by Focal Muscle Vibration.

Front. Neurol. 9:1170.

doi: 10.3389/fneur.2018.01170

\section{Corrigendum: Plasticity Induced in the Human Spinal Cord by Focal Muscle Vibration}

\author{
Lorenzo Rocchi ${ }^{1,2 *}$, Antonio Suppa ${ }^{2,3+}$, Giorgio Leodori ${ }^{2,3}$, Claudia Celletti ${ }^{4}$ \\ Filippo Camerota ${ }^{4}$, John Rothwell ${ }^{1}$ and Alfredo Berardelli ${ }^{2,3}$
}

${ }^{1}$ Department of Clinical and Movement Neurosciences, UCL Queen Square Institute of Neurology, University College London, London, United Kingdom, ${ }^{2}$ Department of Human Neurosciences, University of Rome "Sapienza", Rome, Italy, ${ }^{3}$ Department of Clinical Neurophysiology, IRCCS Neuromed Institute, Pozzilli, Italy, ${ }^{4}$ Physical Medicine and Rehabilitation Division, Sapienza University of Rome, Rome, Italy

Keywords: H-reflex, reciprocal inhibition, muscle vibration, spinal cord, plasticity, somatosensory evoked potentials

\section{A Corrigendum on}

Plasticity Induced in the Human Spinal Cord by Focal Muscle Vibration

by Rocchi, L., Suppa, A., Leodori, G., Celletti, C., Camerota, F., Rothwell, J., et al. (2018). Front. Neurol. 9:935. doi: 10.3389/fneur.2018.00935

In the published article, there was an error regarding the affiliation for Giorgio Leodori. As well as having affiliation two, "Department of Human Neurosciences, University of Rome "Sapienza", Rome, Italy", he should also have affiliation three, "Department of Clinical Neurophysiology, IRCCS Neuromed Institute, Pozzilli, Italy."

The authors apologize for this error and state that this does not change the scientific conclusions of the article in any way. The original article has been updated.

Copyright (c) 2019 Rocchi, Suppa, Leodori, Celletti, Camerota, Rothwell and Berardelli. This is an open-access article distributed under the terms of the Creative Commons Attribution License (CC BY). The use, distribution or reproduction in other forums is permitted, provided the original author(s) and the copyright owner(s) are credited and that the original publication in this journal is cited, in accordance with accepted academic practice. No use, distribution or reproduction is permitted which does not comply with these terms. 